\title{
Article
}

\section{The path of least resistance: Paying for antibiotics in non-human uses}

Hollis, Aidan and Ahmed, Ziana

Available at http://clok.uclan.ac.uk/11841/

Hollis, Aidan and Ahmed, Ziana (2014) The path of least resistance: Paying for antibiotics in non-human uses. Health Policy, 118 (2). pp. 264-270. ISSN 01688510

It is advisable to refer to the publisher's version if you intend to cite from the work. http://dx.doi.org/10.1016/j.healthpol.2014.08.013

For more information about UCLan's research in this area go to

http://www.uclan.ac.uk/researchgroups/ and search for < name of research Group>.

For information about Research generally at UCLan please go to http://www.uclan.ac.uk/research/

All outputs in CLoK are protected by Intellectual Property Rights law, including Copyright law. Copyright, IPR and Moral Rights for the works on this site are retained by the individual authors and/or other copyright owners. Terms and conditions for use of this material are defined in the policies page.

\section{CLoK}

Central Lancashire online Knowledge www.clok.uclan.ac.uk

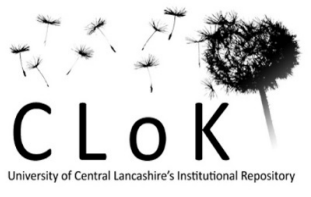




\title{
The path of least resistance: paying for antibiotics in non-human uses
}

August 20, 2014

Keywords: antibiotic resistance; incentives; user fees

\begin{abstract}
Antibiotic resistance is a critical threat to human and animal health. Despite the importance of antibiotics, regulators continue to allow antibiotics to be used in low-value applications -- subtherapeutic dosing in animals, and spraying tobacco plants for blue mold, for example -- where the benefits are unlikely to outweigh the costs in terms of increased resistance. We explore the application of a user fee in non-human uses of antibiotics. Such a fee would efficiently deter low value uses while also providing funding to support the development of the urgently needed new antibiotics.
\end{abstract}




\section{Introduction}

Alexander Fleming's discovery of penicillin in 1928 is regarded as one of the greatest achievements in therapeutic medicine. Antibiotics have improved control of infectious disease, and made surgeries and other treatments much safer and more effective. 258 million courses of antibiotics were prescribed in the US in 2010 [1]. Antibiotics are also central to modern high-density agricultural operations. And yet all the benefits could be easily lost in what critics are calling an antibiotic "apocalypse."

Just as Fleming warned, injudicious use of antibiotics has led to an antimicrobial resistance crisis in which standard treatments are ineffective and infections persist, prolonging illness and increasing risk of death. WHO Director General Dr. Margaret Chan warns that resistance could end modern medicine as we know it [2]. Antibiotic resistance is also creating a substantial economic burden currently estimated as a \$35 billion increase in the US hospital bill.[3] The Centers for Disease Control and Prevention estimates that more that two million Americans are sickened annually with drug resistant infections, and at least 23,000 die as a result. [4] The World Health Organization reports that there were roughly 450,000 new cases of multi-drug resistant tuberculosis in 2012, with mortality of approximately 170,000 . [5]

The resistance crisis is leading to calls for a ban on certain non-human uses of antibiotics, including as animal growth promoters (AGPs), following European countries. The US FDA has gradually imposed stiffer controls on AGPs but there remains considerable flexibility for subtherapeutic dosing with antibiotics for prophylaxis and metaphylaxis under veterinary oversight. Indeed, after Denmark banned the unprescribed used of 
antibiotics as AGPs in 1999, the use of prescribed antimicrobials more than doubled, which compensated for most of the reduction in AGPs [6]. In this paper, we explore user fees as an alternative or complementary policy designed to slow the development of resistance, support funding for new antibiotics, and minimize costs for farmers.

Antimicrobial resistance can be framed as an ecological challenge; selection pressure favors antibiotic-resistant bacteria. Though resistance is a natural phenomenon, it is hastened by a number of controllable factors. Over-prescription, aggressive promotion by pharmaceutical companies, underinvestment in infection control, non-compliance by patients, and weak hospital management practices all contribute to diminishing efficacy of our existing antibiotic resource.

Aggravating the resistance problem is a decline in new drug development. New antibiotics are typically reserved for patients with resistance, limiting the sales volume and hence profits. As a result, only five large multinational companies remain in this field [7] and no new classes of antibiotics have been developed since 1987 [7]. Thus, we urgently need both new mechanisms to support R\&D in antibiotics and policies to preserve existing antibiotics.

Non-human use of antibiotics (NHUA) is a troubling contributor to antimicrobial resistance. Almost 14 million $\mathrm{kg}$ of antibiotics were fed to animals in the US in 2011, comprising $80 \%$ of the total.[9] In fact, many of the antibiotics used to treat humans are also used for growth promotion and infection control in raising livestock, aquaculture and for companion animals. These include macrolides, streptogramins, aminoglycosides and tetracyclines, all classified as being of high importance for treating life-threatening human health conditions.[10] 
According to a growing body of scientific evidence a direct link can be demonstrated between antimicrobial resistance in livestock and in humans $[11,12]$. A recent study found that $36.6 \%$ of industrial livestock workers carried biomarkers associated with methicillinresistant Staphylococcus aureus (MRSA), compared with 19\% of workers at antibiotic-free farms [13]. Furthermore, almost 50\% of industrial livestock workers had bacteria resistant to tetracycline compared with $2.4 \%$ of workers working with antibiotic-free livestock [13]. Collignon et al estimate that cephalosporin use in poultry contributed to over 1500 deaths of people in Europe in 2007 [14]. The frequency of resistance isolates across European countries tended to be at approximately the same levels in animals and food as in people in each country, suggesting that resistant organisms are being transmitted from people to animals, or from animals to food and people [15]. A particularly interesting study in Quebec, Canada explored the effect of a temporary halt in chicken hatcheries' extra-label use of ceftiofur in ovo. Resistance to this important antibiotic fell rapidly not only in chickens, but also in human isolates [16].

Aside from the effect on human health, resistance is also a problem in agriculture, as farmers are increasingly facing resistant strains of bacteria in their farming operations, and are forced to use more costly or less effective antibiotics. Development of policies to limit the development of resistance is therefore of great economic and human significance.

\section{Methods}

We first conduct a literature review, surveying the current data and reports on nonhuman uses of antibiotics. Second, we compare potential policies for limiting non-human uses of antibiotics, focusing on regulatory solutions (bans of various types of applications) and a market-based solution (a user fee). We employ an economics lens to compare aspects 
of the different policies, such as cost, efficiency, equity and enforceability. Third, we illustrate how to determine the level of user fees required to generate a given total annual revenue. Our methodology for this exercise is to calculate the required fee given a range of demand elasticities, using data on 2012 NHUA in the United States. Further description is given below.

\section{Non-human uses of antibiotics}

\section{Agriculture}

The use of antibiotics in agriculture dates back to the 1940s when farming practices transitioned to factory farms with thousands of animals in confinement. The new practices and technology increased productivity and profits, enabling the US to become the world's largest beef producer. This success would not have been possible without antibiotics to combat disease arising from cramped living quarters, poor ventilation and sanitation [17].

Antibiotic use in agriculture can be categorized under four main purposes: therapeutic use, prophylactic use for disease prevention, metaphylactic use for infection control, and as animal growth promoters (AGPs). The latter three purposes constitute subtherapeutic use: low level doses primarily used for infection prevention or changing digestive processes but insufficient to kill bacterial infections [17]. It is estimated that 80$90 \%$ of agricultural antibiotics are used sub-therapeutically for greater weight gain and lower mortality [18]. Subtherapeutic antibiotics are most commonly administered in feed. This mass medication not only prevents disease, facilitating intensive farm operations, but also has an effect on digestive efficiency, increasing weight gain [17]. The Centers for 
Disease Control has recommended that the use of antibiotics as AGPs should be phased out [4], but other subtherapeutic uses continue to be permissible.

\section{Aquaculture}

Antibiotics in aquaculture are primarily used for infection control and increased productivity and are administered through medicated feeds. FDA-approved drugs include sulfadimethoxine, ormetoprim, and oxytetracycline to control for disease in salmonids and catfish and even lobsters. Total US aquaculture industry use is roughly between 100,000 and 200,000 kgs [19].

As much as $80 \%$ of these antibiotics are released into the aquatic environment as fecal and urinary excretion [20]. This leads to a buildup of antibiotics in aquatic systems, a high presence of drug residues in fish products, and ultimately, increased antimicrobial resistance. $74-100 \%$ of wild fish in close proximity to treated ponds contain quinolone residues.

Cabello et al conclude that available evidence "strongly suggests" that aquaculture is an important source for the passage of a large amount of antimicrobials into the environment, where they select for resistant bacteria [21]. Furthermore, there is evidence of substantial transfer of bacteria from marine to terrestrial environments.

\section{Companion Animals}

Companion animals represent a disproportionate share of NHUA. According to the DANMAP, although the pet and cat population is only two-thirds the size of the livestock population in Denmark, it consumes 6 times as many animal daily doses [22]. Companion animals consumed $45 \%$ of the total weight of fluoroquinolones and $55 \%$ of cephalosporins used in animals in Denmark in 2003 [22]. While national monitoring programs of 
antimicrobial resistance exclude companion animals, US consumption is likely proportional to Denmark.

In the US, more than $50 \%$ of dogs surveyed received an antimicrobial of critical importance to human medicine in the previous year [23]. While few studies have been done, households pets are recognised as a source of human infection with multidrug resistant $S$. Typhimurium and campylobacteriosis among young children [24]. Cases of MRSA transmission have been reported between animals and pet owners and veterinarians in Canada, the UK and in Ireland [24]. The transmission of resistance is aggravated by the rapid increase in use of critical classes of antibiotics to treat enteric cases in companion animals [25]. These include third and fourth generation cephalosporins, nitroimidazoles and penicillin B-lactam inhibitors.

\section{Other}

Antibiotics have many other applications. Nystatin is used to prevent spread of mold on objects, including works of art [26]. Tetracycline is a component of "Compound-X Antifouling Paint Additive" to be added to marine paint to inhibit the growth of algae and barnacles on ships' hulls. [27] Oxytetracycline is used prophylactically to control the contamination of plant tissue and as a topical therapeutic treatment of bacterial disease in fruit trees with about 10,000 to 20,000 kgs used annually [28], but resistance has developed to streptomycin in erwinia amylovora, the causal agent of Fire Blight [29].

In what must be one of greatest ironies of public health, streptomycin is even "labeled" for use on tobacco plants, and helps to improve productivity in that industry. ${ }^{1}$

\footnotetext{
${ }^{1}$ See, for example, Ag Streptomycin, http://www.manainc.com/products/ag-streptomycin/ accessed August 172013.
} 


\section{The range of values in different uses}

Antibiotics have widely varying associated benefits and costs in different uses. It is clear that subtherapeutic use in animals typically has a much lower value than therapeutic use in animals or people. Roughly $10 \mathrm{~m}$ kgs of antibiotics are used as AGPs annually in the US. Since banning AGPs would cost up to $\$ 2.5$ billion annually, as reported by the National Research Council, the net value of antibiotics as AGPs averages roughly $\$ 250 / \mathrm{kg}$. In comparison, a kilogram of ceftiofur or cefquinome used therapeutically could treat 300 fullsize cattle for respiratory disease. At $\$ 1000$ per head, this implies a value of approximately $\$ 300,000 / \mathrm{kg}$ of antibiotic. The value of antibiotics in treating humans is even higher, assuming we assign a value exceeding \$1000 per head.

The extreme variation in values suggests that, if anything, the focus should be on preserving the effectiveness of antibiotics for the high-value uses. At present, however, countries permit a wide variety of uses, without much consideration of protecting applications that have higher value from resistance created by low-value uses.

\section{Policy Alternatives}

Many alternatives have been proposed to promote more judicious conservation practices, including restricting uses. For example, the FDA banned fluoroquinolones for poultry in 2005. The EU has banned AGPs, following the lead of some countries. In 2012 the FDA issued new regulations requiring food animal producers to voluntarily phase out the use of antibiotics for growth promotion or feed efficiency and then in 2013 asked drug companies to remove growth promotion from the list of approved uses on product labels $[30,31]$. Initial steps to phase in veterinary oversight for animal drug products were also 
laid out. Even if voluntary compliance is effective, we can still expect very substantial volumes of antibiotics to be used for a variety of non-human uses..

We explore, in the following sections, the possibilities of imposing a ban on certain non-human uses of antibiotics, and compare this with the option of a user fee.

\section{Option 1: A Ban}

A ban could be applied to the use of antibiotics as AGPs, or more broadly to all subtherapeutic uses, or to all uses not under the supervision of a veterinarian. The latter would allow scope for widespread use of antibiotics, including as AGPs.

In Sweden, which enacted a ban on AGPs in 1986, sales of antibiotics for animals fell by 30 tons from 1986-2009 [32]. In Denmark a ban of avoparcin and virginiamycin decreased antimicrobial consumption by $51 \%$ in swine, and $90 \%$ in poultry [32]. Evidence from Denmark, the Netherlands, and the UK shows that the decline in antibiotic usage slowed the development of resistance across a range of bacteria and resistance profiles [32, 33]. The question of whether the ban translates into lower resistance for humans is more difficult to answer. Some studies indicate that the termination of AGPs in Denmark led to a decline in the prevalence of streptogramin resistance among E. faecium in humans, while others suggest an increase in resistance among E. faecalis to erythromycin due to increased therapeutic use of tylosin following the ban [33]. The principal public health goal to reduce resistance in the food animal reservoir, however, was achieved.

There are, however, many objections to the implementation of a selective ban on NHUA. First, a ban might not be as effective as hoped. In the Netherlands, therapeutic drug use increased following the AGP ban, leaving total antibiotic use at least temporarily unchanged [32]. The challenge is that many antibiotics are used for therapeutic purposes 
and growth promotion simultaneously. For example, the FDA lists the following "indications for use" of erythromycin in chicken feed: "as an aid in the prevention and reduction of lesions and in lowering severity of chronic respiratory disease; growth promotion and feed efficiency; improving pigmentation." ${ }^{2}$ It may be impossible to determine whether a given product was used to reduce lesions or to improve pigmentation. Given the range of uses, it is difficult to draw a clean line between prophylactic and nontherapeutic uses. A ban on AGPs only would fail to stop all low value uses.

Second, a ban would be costly. The Swedish and Danish AGP bans resulted in increased mortality rates, decreased feed efficiency, increased weaning periods, and decline in piglets per sow [34]. A ban would require increased investment in infection control, hygiene management practices and veterinary aid to treat sick animals that would have remained healthy under subtherapeutic antibiotics. Evidence from the Netherlands, Denmark and the UK all suggest that use of certain classes of therapeutic antibiotics actually increased following the ban of AGPs [32], suggesting increased costs for therapeutic treatment.

In the US, banning AGPs was predicted to increase production costs by an estimated $\$ 1.2-2.5$ billion per year [35]. Other studies are summarized in Table 1. A more comprehensive ban of all subtherapeutic use would increase production costs much more.

\footnotetext{
2 US Code of Federal Regulations, "New Animal Drugs for Use in Animal Feeds" 21CFR558.62(c)(vii), revised April 12013.
} 


\section{Table 1: Estimated Cost of Total Subtherapeutic Ban to Consumers}

\begin{tabular}{|l|l|l|}
\hline Study & $\begin{array}{l}\text { Total National Extra Cost } \\
\text { (dollars per year) }\end{array}$ & Industry Affected \\
\hline $\begin{array}{l}\text { Hayes et al. (2001) } \\
\text { [36] }\end{array}$ & $\$ 748$ million & Pork \\
\hline USDA (1978) [37] & $\$ 1.24$ billion & All \\
\hline $\begin{array}{l}\text { National Research } \\
\text { Council (1999) [35] }\end{array}$ & $\begin{array}{l}\text { \$1.2 billion (with substitutes) } \\
\$ 2.5 \text { billion (no substitutes) }\end{array}$ & All \\
\hline $\begin{array}{l}\text { Brorsen et al. (2002) } \\
\text { [38] }\end{array}$ & $\$ 586$ million & Poultry and Pork \\
\hline
\end{tabular}

Third, the choice of what to ban is not straightforward. Apart from growth promotion, prophylactic and metaphylactic use for disease, off-label drug use is common, since few animal-specific drugs have been approved for minor species [35]. Furthermore, on farms without diagnostic capabilities, undiagnosed therapeutic use of antibiotics is both useful and prevalent [39], and there is a shortage of veterinarians to diagnose and prescribe all needed antibiotics.

\section{Option 2: User fees for NHUA}

Since existing antibiotics are a finite resource that are used up through the development of resistance, a charge for their use is properly described as a user fee. This would be comparable to other fees for depleting scarce resources, such as royalties for oil and gas production or stumpage for logging. These fees recognize that the user is taking something of value. Similarly, a NHUA user fee would be a payment for using up the potency of the drug. At present, the price for draining this invaluable public resource is zero, and this is certain to lead to over-consumption. 
A user fee would deter low-value usage of antibiotics. Like a ban, this would likely result in reduced resistance because of decreased selective pressure. The higher the fee, the greater the reduction in use. There would be corresponding benefits for human and animal health.

\section{Comparing a ban and user fees}

The user fee has several advantages over a ban [40]. First, a ban on select uses of antibiotics would require monitoring and enforcement to be effective. This would be costly, but failure to monitor would create advantages for unscrupulous businesses that claimed a therapeutic purpose while benefiting from growth promotion. With millions of individuals and firms using antibiotics in non-human applications, monitoring and enforcement of a ban at the individual level are likely to be costly. User fees, in contrast are relatively easy to enforce and administer, since they can be imposed at the manufacturing or importing stage. This is an important advantage of user fees [41].

Second, user fees can efficiently target all low value uses, regardless of the description of the activity. Some producers may substitute away from antibiotics to vaccinations or improved animal management practices due to higher prices, while others without good substitutes may continue antibiotic use. Providing farmers and veterinarians with the option to decide whether antibiotics confer enough benefits to make it worth the increased price, rather than relying on the intrusive, indiscriminate hand of government leads to a more efficient outcome, in the sense that it can achieve a similar reduction in resistance at lower total cost. For a more general exposition of this point, see [42]. The US tradeable emissions market in SO2 allowances was an efficient policy response because it took 
account of the varying abatement costs of different producers; one would expect the same type of results from a user fee on NHUA. [43]

Third, the user fee promises a more equitable option since all users make a contribution proportional to the volume of antibiotics they use. In comparison, a ban is only costly to firms that are forced to stop using antibiotics in the banned uses, while other firms, which continue to use antibiotics in permitted applications and thus contribute to resistance, are not penalized at all. This is a subtle violation of the "polluter pays" principle [44].

Fourth, ideally, user fees would generate revenues that could be used to support basic research into antimicrobials or to fund reward systems encouraging both development and improved use of antimicrobials. A reward system that recognized the value of new antimicrobials, while also protecting them from overuse, would, we think, generate the greatest benefits. Examples of this kind of reward system are described in $[45,46]$.

International replicability is the fifth advantage of the user fee over the ban given the global nature of resistance. Governments would be motivated to collect revenues in the case of a fee; in contrast, a ban disadvantages local producers while providing no revenues to government. Thus, a user fee could be incorporated in a treaty and would be more likely to be enforced.

Sixth, a user fee would create lower costs for agriculture than a ban, if set appropriately. To assess the costs, however, we first need to propose a given level of fee. We discuss this point below. 


\section{Results: Setting a user fee}

Ideally, a user fee would be based on the marginal impact of use on the cost created by resistance, which is effectively unquantifiable. One plausible alternative is to set the user fee so that it supports the development of replacement antibiotics. Credible estimates of the development cost of new drugs range from $\$ 500 \mathrm{~m}$ to over $\$ 1.5 \mathrm{bn}$ per new approved drug [47]. Antibiotics may differ systematically in their cost of development. We have calculated a user fee for US NHUA that would raise $\$ 500 \mathrm{~m}$ annually, which would make a significant contribution towards paying for research into or rewards for new antibiotics, as well as supporting stewardship programs. Our methodology for this exercise is to calculate the required fee given a range of demand elasticities, using data on 2012 NHUA in the United States.

The usage and wholesale pricing of antibiotics used commonly for animals (but not crops) are presented in Table 2. The reported Defined Daily Doses (DDDs), which indicate a standard usage amount per day, are for humans. We calculate a rough measure of the total US expenditure on NHUA: notably, expenditure does not reflect formulation costs or veterinary costs. Formulated antibiotics for therapeutic use would typically be approximately ten to twenty times as expensive as the prices shown here.

\section{Table 2: Total Antimicrobial Consumption by Class in the US}

\begin{tabular}{|l|r|l|l|l|l|r|l|}
\hline $\begin{array}{l}\text { Antimicrobial } \\
\text { Class }\end{array}$ & $\begin{array}{l}\text { Animal } \\
\text { Use (Kg) }\end{array}$ & $\begin{array}{l}\text { Human } \\
\text { Use (Kg) }\end{array}$ & $\begin{array}{l}\text { Total Use } \\
\mathbf{( K g )}\end{array}$ & $\begin{array}{l}\text { Averag } \\
\text { e DDD } \\
(\mathbf{g})\end{array}$ & $\begin{array}{l}\text { Total Animal } \\
\text { Usage (DDD) }\end{array}$ & $\begin{array}{l}\text { Price } \\
\mathbf{( \$ / k g )}\end{array}$ & $\begin{array}{l}\text { Animal } \\
\text { Expenditures }\end{array}$ \\
\hline Aminoglycoside & 214,895 & 6,485 & 221,380 & 0.599 & $358,457,048$ & $\$ 28.5$ & $\$ 6,124,507.5$ \\
\hline Cephalosporins & 26,611 & 496,910 & 523,521 & 2.77 & $9,606,859$ & $\$ 75$ & $\$ 1,995,825$ \\
\hline Ionophores** & $4,123,259$ & na & $4,123,259$ & 1.56 & $2,644,227,099$ & $\$ 30$ & $\$ 123,697,770$ \\
\hline
\end{tabular}




\begin{tabular}{|l|r|r|r|r|r|r|r|}
\hline Macrolides & 582,836 & 164,028 & 746,864 & 1.07 & $544,706,542$ & $\$ 55$ & $\$ 32,055,980$ \\
\hline Lincosamides & 190,101 & 71,455 & 261,556 & 1.65 & $115,212,727$ & $\$ 50$ & $\$ 9,505,050$ \\
\hline Penicillins & 880,163 & $1,460,421$ & $2,340,584$ & 3.76 & $234,085,904$ & $\$ 30$ & $\$ 26,404,890$ \\
\hline Sulfas & 371,020 & 481,664 & 852,684 & 1.91 & $194,251,309$ & $\$ 33$ & $\$ 12,243,660$ \\
\hline Tetracyclines & $5,642,573$ & 113,832 & $5,756,405$ & 1 & $5,642,573,000$ & $\$ 28$ & $\$ 157,992,044$ \\
\hline $\begin{array}{l}\text { Not } \\
\text { independently } \\
\text { reported*** }\end{array}$ & $1,510,572$ & na & $1,510,572$ & 1.56 & $968,722,900$ & $\$ 30$ & $\$ 45,317,160$ \\
\hline Total: & $13,542,030$ & $3,289,175$ & $16,831,205$ & & $10,711,843,388$ & & $\$ 246,321,956$. \\
\end{tabular}

Notes. Data on quantities from $[9,48]$. Data on prices are drawn from a search of prices offered on Alibaba in August 2013. DDDs are taken from the WHO ATC/DDD Index 2013 and averaged by class. *Includes aminocoumarins, amphenicols, diaminopyrimidines, fluoroquinolones, glycolipids, pleuromutilins, polypeptides, quinoxalines, and streptogramins. **The DDD is the average of other commonly used antibiotics.

Given the information in table 2, a simple simulation enables us to estimate the user fee per DDD required to raise a given revenue, the impact on food production costs, and the decrease in antibiotics consumed. The key parameter is the elasticity of demand for NHUA, $\varepsilon$. We assume that $\varepsilon=-0.1$ or $\varepsilon=-0.5$ as limiting cases. ${ }^{3}$ An elasticity of -0.1 implies that producers do not significantly reduce antibiotic consumption even with a substantial increase in prices, which we think is realistic given the low prices of antibiotics compared to their value to producers. As shown in Table 3, a fee between $\$ 0.0525-\$ 0.114$ per DDD equivalent is needed to raise $\$ 500$ million per year. ${ }^{4}$

Table 3: Estimated User Fee and Associated Impacts

\footnotetext{
${ }^{3}$ Assume a demand function for antibiotics given by $q=K p^{\varepsilon}$, where $\varepsilon<0$ represents elasticity and $K$ is an unknown scalar. Demand for antibiotics in agricultural production is assumed to be based on the cost savings it delivers. We solve for $K$ at current prices and quantities with the assumed value of $a$ and then solve for the user fee that raises $\$ 500 \mathrm{~m}$.

${ }^{4}$ To determine the fee per kg, multiply the fee per DDD by 1000 and divided by the average DDD in grams.
} 


\begin{tabular}{|l|r|r|}
\hline & Elasticity of -0.1 & \multicolumn{1}{|c|}{ Elasticity of -0.5 } \\
\hline Estimated Fee (\$/DDD) & $\$ 0.0525$ & $\$ 0.114$ \\
\hline $\begin{array}{l}\text { Total Additional Cost of Food } \\
\text { Production* (\$/year) }\end{array}$ & $\$ 524,144,652$ & $\$ 709,804,588$ \\
\hline $\begin{array}{l}\text { Decrease in Antibiotic Use } \\
\text { (DDDs per year) }\end{array}$ & $1,200,625,755$ & $59.0 \%$ \\
\hline $\begin{array}{l}\text { Decrease in Non-Human } \\
\text { Antibiotic Use (\% DDDs) }\end{array}$ & $11.2 \%$ & \\
\hline
\end{tabular}

The elasticity assumption is critical. If the elasticity is -0.1 , the reduction in use of antibiotics is relatively small. The user fee is then low, since there are more units sold. The incremental cost in terms of food production consists of two elements: there is $\$ 500 \mathrm{~m}$ in additional costs created by the higher prices of antibiotics because of the user fee; and another $\$ 24 \mathrm{~m}$ that arises from higher costs for producers because of reduced use of antibiotics. If the $\$ 500 \mathrm{~m}$ raised by the user fee ultimately supports the development of new antibiotics, the current "cost" to agricultural production is offset by future reductions in cost because of future availability of effective antibiotics. With higher elasticity, there is a much larger reduction in antibiotic use, so the user fee needs to be higher to raise the same revenues. The impact on costs is greater because of a greater reduction in consumption of antibiotics.

\section{Discussion}

How does the user fee compare with a ban on AGPs? As we discussed above, an AGP ban is expected to increase costs of production by roughly $\$ 2.5 \mathrm{bn}$ without substitution; with substitution and adjustment, the net cost is expected to be approximately $\$ 1.2 \mathrm{bn}$. This is substantially above the expected cost of a user fee; and of course, a ban would not 
generate any funding for antimicrobial R\&D. Depending on how it was implemented, a ban could result in a greater decrease in NHUA, but there would be real productivity costs. And it is unclear that a ban in the US would be accompanied by bans in other countries that use substantial volumes of antibiotics in non-human uses. A user fee is a more flexible instrument, which could be raised or lowered as needed. A user fee could also be set to increase automatically, giving producers time to adjust. Even if a ban on AGPs were effective, it would not address the substantial NHUA for other purposes, while a user fee could apply to all NHUA.

A substantial part of NHUA is in the ionophore class, which is little used in humans. It is therefore hard to make a cogent case for banning ionophores as AGPs, but a user fee still makes sense. Like other antibiotics, ionophores are subject to the development of resistance [49], and like other antibiotics, they have high-value and low-value uses. For example, monensin is used both as an AGP and to prevent the parasitic disease coccidiosis. A user fee would help to protect the high value uses from increased resistance, while also raising funds to support further research into antibiotics. Some ionophores -- such as nystatin -- are also extensively used in humans, and protecting these products is of value.

We have proposed a user fee only on non-human uses of antibiotics. Should fees also be imposed on human antibiotic consumption, given the more direct link between human overconsumption and resistance? The presence of health insurance complicates this question, as consumers would not feel the price increase and the impact on use would be negligible. A user fee applied to human use would also likely be less likely to be applied in other countries. Thus, we believe that it would be most practical to apply a user fee only to non-human uses. 
Antimicrobial resistance is a complex phenomenon and while non-human use of antibiotics is not the sole source of resistance, it is likely to be a meaningful contributor. In this paper we have catalogued the varied non-human uses of antibiotics and their differing economic values. In comparing the policy options of a ban and a user fee, we conclude a user fee on non-human use is the preferred policy option that would help to achieve an "integrated" strategy to conserve existing antibiotics while promoting the development of new ones [50]. A user fee could also be a useful complementary tool even if a ban is applied to the use of antibiotics for growth promotion. Finally, we calculate a fee between $\$ 0.0525$ $\$ 0.114$ per DDD equivalent is needed to raise $\$ 500$ million per year, a credible estimate of the development cost of new drugs.

\section{References}

[1] L. A. Hicks, T. H. Taylor Jr., R. J. Hunkler, U.S. outpatient antibiotic prescribing, 2010. N. Engl. J. Med. 368, 1461-1462 (2013).

[2] Chan M. Antimicrobial resistance in the European Union and the world [Internet]. Copenhagen: WHO; 2012 March 14 [cited 2013 Aug 13]. Available from: http://www.who.int/dg/speeches/2012/amr 20120314/en/

[3] Wallinga D, Burch D. Does adding routine antibiotics to animal feed pose a serious risk to human health? BMJ 2013 July ; 347:f4214. doi: 10.1136/bmj.f4214 [4] Centers for Disease Control. "Antibiotic Resistance Threats in the United States, 2013."

[5] World Health Organization, Multidrug-resistant tuberculosis (MDR_TB) October 2013

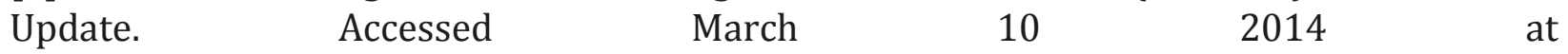
http://www.who.int/tb/challenges/mdr/mdr tb factsheet.pdf?ua=1

[6] DANMAP (Danish Integrated Antimicrobial Resistance Monitoring and Research Programme). DANMAP 2012 - Use of antimicrobial agents and occurrence of antimicrobial resistance in bacteria from food animals, food and humans in Denmark,

[7] Coates AR, Halls G, Hu Y. Novel classes of antibiotics or more of the same? $\mathrm{Br} \mathrm{J}$ Pharmacol. 2011 May ; 163(1): 184-94. doi: 10.1111/j.1476-5381.2011.01250.x. 
[8] World Economic Forum. Global Risks 2013. Switzerland: World Economic Forum; 2013 78 p. $\quad$ Report $\quad$ No.: $8 . \quad$ Available from: http://www3.weforum.org/docs/WEF GlobalRisks Report 2013.pdf

[9] FDA. 2011 Summary Report on Antimicrobials Sold or Distributed for Use in FoodProducing Animals [Internet]. Food and Drug Administration; 2013 [cited 2013 Aug 13]. 4 p. $\quad$ Report $\quad$ No.: $3 . \quad$ Available from: http://www.fda.gov/downloads/ForIndustry/UserFees/AnimalDrugUserFeeActADUFA/U CM338170.pdf

[10] Health Canada. Current Thinking on Risk Management Measures to Address Antimicrobial Resistance Associated with Use of Antimicrobial Agents in Food-Producing Animals [Internet]. Health Canada; 2005 June [cited 2013 Aug 13]. 41 p. Available from: http://www.hc-sc.gc.ca/dhp-mps/alt formats/hpfb-dgpsa/pdf/vet/amr-ram reprap 06 05-eng.pdf

[11] Harrison, E. M et al. (2013), Whole genome sequencing identifies zoonotic transmission of MRSA isolates with the novel mecA homologue mecC. EMBO Mol Med, 5: 509-515. doi: 10.1002/emmm.201202413

[12] Spoor LE, 2013. Livestock Origin for a Human Pandemic Clone of CommunityAssociated Methicillin-Resistant Staphylococcus aureus.MBio. 2013 Aug 13;4(4). pii: e00356-13. doi: 10.1128/mBio.00356-13.

[13] Rinsky JL, Nadimpalli M, Wing S, Hall D, Baron D, Price LB et al. Livestock-Associated Methicillin and Multidrug Resistant Staphylococcus aureus Is Present among Industrial, Not Antibiotic-Free Livestock Operation Workers in North Carolina. PLoS ONE. 2013 Jul; 8 (7): e 67641.

[14] Collignon P, Aarestrup FM, Irwin R, McEwen S. Human deaths and third-generation cephalosporin use in poultry, Europe [letter]. Emerg Infect Dis. 2013 Aug; 19(8). http://dx.doi.org/10.3201/eid1908.120681

[15] European Food Safety Authority and European Centre for Disease Prevention and Control. "The European Union Summary Report on antimicrobial resistance in zoonotic and indicator bacteria from humans, animals and food in 2011." EFSA Journal 2013; 11(5): 3196.

[16] Dutil, Lucie, et al. "Ceftiofur resistance in Salmonella enterica serovar Heidelberg from chicken meat and humans, Canada." Emerging infectious diseases 16.1 (2010): 48.

[17] Lessing A. Killing Us Softly: How Sub-Therapeutic Dosing of Livestock Causes DrugResistant Bacteria in Humans. B.C. Envtl. Aff. L. Rev. 2010 Jul; 37 (2): 463.

[18] Lusk JL, Norwood FB, Pruitt JR. Consumer Demand for a Ban on Antibiotic Drug Use in Pork Production. Amer. J. Agr. Econ. 2006 Nov; 88(4):1015-1033. 
[19] Benbrook CM. Antibiotic Drug Use in US Aquaculture [Internet]. Institute for Agriculture and Trade Policy; 2002 Feb [cited 2013 Aug 13]. 18 p. Available from http://m.iatp.org/files/421 237397.pdf

[20]. Romero J, Feijoo CG, Navarrete P. Antibiotics in Aquaculture -- Use, Abuse, Alternatives. in Carvalho ED, David GS, Silva RJ Health and Environment in Aquaculture. Intech Publishers. 2012. DOI:10.5772/28157

[21] Cabello FC. Heavy use of prophylactic antibiotics in aquaculture. Environ Microbiol. 2006 Jul;8(7):1137-44.

[22] Lloyd DH. Reservoirs of antimicrobial resistance in pet animals. Clin Infect. Dis. 2007 Sep ; 45 Suppl 2: S148-52.

[23] Baker SA, Van-Balen J, Lu B, Hillier A, Hoet AE. Antimicrobial drug use in dogs prior to admission to a veterinary teaching hospital. Journal of the American Veterinary Medical Association, 2012; 241(2): 210-217.

[24] Jensen, Lars B., et al. "Human health risks associated with antimicrobial use in animals." Guide to Antimicrobial Use in Animals Oxford (2008): 13-26.

[25] Anholt, Rae. "Informatics and the Electronic Medical Record for Syndromic Surveillance in Companion Animals: Development, Application and Utility." (2013). University of Calgary, $\mathrm{PhD}$ thesis.

[26] Brommelle NS. The Restoration of Damaged Art Treasures in Florence and Venice. Journal of the Royal Society of Arts 118, no. 5165 (1970): 260-269.

[27] AMOG Consulting. "Hull fouling as a vector for the translocation of marine organisms, Phase 3." Department of Agriculture, Fisheries and Forestry-Australia. 2002.

[28] Falkiner FR. The consequences of antibiotic use in horticulture. Journal of Antimicrobial Chemotherapy 41(4) (1998): 429-431.

[29] McGhee GC, Bellomo L, Blumer SE, Sundin GW. 2007. Emergence and progression of streptomycin resistance in Erwinia amylovora in Michigan. 11th International Workshop on Fire Blight, Paper 061.

[30] Food and Drug Administration. Guidance for Industry \#209. The Judicious Use of Medically Important Antimicrobial Drugs in Food-Producing Animals. April 13, 2012.

[31] Food and Drug Administration. Guidance for Industry \#213. New Animal Drugs and New Animal Drug Combination Products Administered in or on Medicated Feed or Drinking Water of Food-Producing Animals: Recommendations for Drug Sponsors for Voluntarily Aligning Product Use Conditions with GFI \#209. December, 2013. 
[32] Cogliani, Carol, Herman Goossens, and Christina Greko. "Restricting antimicrobial use in food animals: lessons from Europe." Microbe 6, no. 6 (2011): 274.

[33] World Health Organization. "Impacts of antimicrobial growth promoter termination in Denmark." March 2003. WHO/CDS/CPE/ZFK/2003.1

[34] Hogberg, Michael G., Kellie Curry Raper, and James F. Oehmke. "Banning subtherapeutic antibiotics in US swine production: a simulation of impacts on industry structure." Agribusiness 25, no. 3 (2009): 314-330.

[35] National Research Council. The use of drugs in food animals : benefits and risks. Washington DC: National Academy Press, 1999.

[36] Hayes, Dermot J., Helen H. Jensen, Lennart Backstrom, and Jaćinto Fabiosa. "Economic impact of a ban on the use of over the counter antibiotics in US swine rations." The International Food and Agribusiness Management Review 4, no. 1 (2001): 81-97.

[37] USDA, Economic Effects of a Prohibition on the Use of Selected Animal Drugs. Commercial Agriculture Division, Economic Research Service, 1978.

[38] Brorsen, B. Wade, Terry Lehenbauer, Dasheng Ji, and Joseph Connor. "Economic impacts of banning subtherapeutic use of antibiotics in swine production." Journal of Agricultural and Applied Economics 34, no. 03 (2002).

[39] World Health Organization. WHO global strategy for containment of antimicrobial resistance. World Health Organization, 2001.

[40] Hollis A, Ahmed Z. Preserving antibiotics, rationally. New England Journal of Medicine, 2013; 369(26): 2474-2476.

[41] National Center for Environmental Economics, EPA, Chapter 4 Regulatory and NonRegulatory Approaches to Pollution Control in Guidelines for Preparing Economic Analyses, December 2010.

[42] Baumol, William J. "On taxation and the control of externalities." American Economic Review (1972): 307-322.

[43] Newell, Richard G., and Robert N. Stavins. "Cost heterogeneity and the potential savings from market-based policies." Journal of Regulatory Economics 23, no. 1 (2003): 4359.

[44] Tobey, James A., and Henri Smets. "The Polluter-Pays Principle in the Context of Agriculture and the Environment." The World Economy 19.1 (1996): 63-87. 
[45] Outterson K, Pogge T, Hollis A. "Combatting Antibiotic Resistance through the Health Impact Fund." In The Globalization of Health Care, Glenn Cohen, ed., Oxford University Press, 2013.

[46] Anderson J. De-linking Return on Investment from Sales Volume for New Antibacterials. Presentation at Brookings Institution, Feb 272013.

[47] Morgan S, Grootendorst P, Lexchin J, Cunningham C, Greyson D. The cost of drug development: A systematic review. Health Policy 2011; 100(1):4-17.

[48] FDA. Drug use review. April 5 2012. Accessed 23 Aug 2013 at http://www.fda.gov/downloads/Drugs/DrugSafety/InformationbyDrugClass/UCM319435 .pdf

[49] Chapman, H. D., and T. Rathinam. "Sensitivity of field isolates of Eimeria to Monensin in the Turkey." Avian diseases 51.4 (2007): 954-957.

[50] Kesselheim, Aaron S., and Kevin Outterson. "Fighting antibiotic resistance: marrying new financial incentives to meeting public health goals." Health Affairs 29, no. 9 (2010): 1689-1696. 